\title{
Desempenho de bovinos da raça nelore suplementados com cromo orgânico
}

\section{The performace of nelore steers supplemented with organic chromium}

\author{
Carlos Henrique Montemór ${ }^{1 *}$; Wilmar Sachetin Marçal ${ }^{2}$
}

\section{Resumo}

\begin{abstract}
O objetivo desse experimento foi avaliar o efeito da suplementação com cromo orgânico sobre o peso corporal e ganho de peso de bovinos da raça Nelore. Utilizaram-se 20 bezerros, inteiros, com peso inicial de $179 \mathrm{~kg}$ e 6 meses de idade, distribuídos ao acaso em dois tratamentos com 10 animais, sendo um grupo controle e outro suplementado com cromo orgânico ( $1 \mathrm{mg}$ de cromo na forma de carboaminofosfoquelato de cromo), veiculado em sal mineral com estimativa de consumo em torno de 50g/bezerro/dia. O lote controle recebeu o mesmo sal mineral sem o cromo, com a mesma estimativa de consumo. Ambos foram fornecidos ad libitum e os animais mantidos em piquetes de Brachiaria brizantha e $B$. decumbens, em forma de rodízio durante 348 dias. Para avaliação do ganho de peso, os animais foram pesados após 14 horas de jejum de alimentos sólidos e líquidos, a cada 10 dias nos primeiros 40 dias de experimento e após, a cada 28 dias. A suplementação com $\mathrm{Cr}$ orgânico em bovinos Nelore influenciou $(\mathrm{P}<0,05)$ o peso corporal aos 210 dias, sendo $258,2 \mathrm{~kg}$ e $252,28 \mathrm{Kg}$ para o grupo suplementado com cromo orgânico e controle, respectivamente.
\end{abstract}

Palavras-chave: Minerais, desempenho produtivo, peso corporal

\begin{abstract}
The objective of this experiment was to evaluate the effects of organic chromium supplementation on the body weight and weight gain of Nelore steers. Twenty calves were used, with initial weight of $179 \mathrm{~kg}$ and 6 months of age. They were distributed in two groups, being 10 animals per group. The experimental group received an organic chromium ( $1 \mathrm{mg}$ of carboaminofosfoquelato of chromium) per day. The mineral salt consumption was estimated for $50 \mathrm{~g} / \mathrm{animal} /$ day. The animals in the control group received the same mineral salt without chromium, in the same consumption. The mineral salt was furnished ad libitum and the animals were maintained in pickets with Brachiaria brizantha and $B$. decumbens pasture, with rotation during 348 days. For weight gain evaluation, the animals were weighed after 14 hours of solids and liquids fast, every 10 days in the first 40 days of the experiment. After this, steer weights were recorded at 28 days intervals. The organic $\mathrm{Cr}$ supplementation in Nelore steers there was influence $(\mathrm{P}<0.05)$ in the body weight it was on day $210,258.2 \mathrm{~kg}$ and $252.28 \mathrm{~kg}$ for the organic chromium supplemented and for the control group, respectively.
\end{abstract}

Key words: Beef cattle, productive performance, body weight

1 Médico Veterinário, Mestre em Ciência Animal pela Universidade Estadual de Londrina/UEL. Londrina-PR. E-mail: chmontemor@uol.com.br

2 Professor Associado da Universidade Estadual de Londrina/UEL. Londrina-PR.

* Autor para correspondência 


\section{Introdução}

O Brasil tem aproximadamente $80 \%$ de seu território concentrado na faixa tropical, área que apresenta potencial para produção de carne e leite conduzidos nos sistemas em pastejo (LOPES et al., 2004). No entanto, a maior dificuldade para a produção a pasto é a ocorrência da estacionalidade de produção de forragens. Estas variações no sistema extensivo de criação influem no desempenho dos animais contribuindo para que o crescimento ponderal seja interrompido (GALATI; EZEQUIEL, 2003). Portanto, há necessidade de se obter ganhos em produtividade, minimizando os efeitos negativos da sazonalidade de forrageiras tropicais (GÓES et al., 2003). Por isso, a suplementação mineral é considerada obrigatória na produção pecuária.

Os minerais desempenham papel fundamental em diversas reações no metabolismo animal, atuando nos mais diferentes sistemas orgânicos com diversidade de funções e influenciando diretamente no desempenho bovino (MORAES, 2001).

Com o avanço da produção de bovinos de corte, as exigências nutricionais aumentaram e novos microelementos minerais e formas de suplementação entraram no cenário da produção (MORAES, 2001). Nesse sentido, o uso de minerais orgânicos na alimentação de ruminantes tem proporcionado respostas positivas na produção, como é o caso do Cromo orgânico $(\mathrm{Cr})$.

As exigências de $\mathrm{Cr}$ ainda não são bem conhecidas. Só recentemente os ruminantes passaram a ser suplementados com $\mathrm{Cr}$, mas ainda existem dúvidas quanto aos seus reais efeitos (ZANETTI et al., 2003). Sua suplementação pode ser realizada em animais de alta produção ou em animais sob condição de estresse, como na desmama (MORAES, 2001). O Cr pode estar envolvido em várias funções biológicas, e como componente integral do Fator de Tolerância à Glicose (GTF), se liga à insulina, a qual é responsável pelo transporte da glicose e aminoácidos para o interior da célula por receptores da membrana celular. Tal otimização da atividade da insulina resulta na melhor regulação da glicose capturada pela célula e em conseqüência no melhor controle da concentração de glicose sangüínea e utilização máxima do potencial energético (PECHOVÁ et al., 2002), sendo, desta forma, um mineral traço essencial para o metabolismo normal de carboidratos, lipídios e hormônios do crescimento (NRC, 1989; MERTZ, 1993; POLLARD; MORAES, 2001; RICHARDSON; KARNEZOS, 2002).

Alguns resultados de pesquisa, na literatura, têm demonstrado que o Crénecessário para o crescimento e síntese de proteína e que a suplementação pode melhorar a performance devido ao aumento do metabolismo energético (MERTZ, 1993).

$\mathrm{Na}$ República Tcheca demonstraram-se maior concentração de glicose sangüínea e menor de corpos cetônicos em vacas leiteiras no período periparto, além de experimentos com suplementação de $\mathrm{Cr}$ em suínos, bovinos, ovinos e aves terem demonstrado que o $\mathrm{Cr}$ melhora a qualidade da carcaça pelo aumento do rendimento em carne e decréscimo na quantidade de gordura (PECHOVÁ et al., 2002).

Pollard, Richardson e Karnezos (2002), relataram que os efeitos do $\mathrm{Cr}$ sobre a performance e crescimento dos animais têm sido variáveis e menos consistentes do que os efeitos no sistema imune em bovinos de corte e Gottschall et al. (2004) afirmaram que a produção de bovinos de corte deve ser eficiente e econômica pela taxa de crescimento e ganho de peso dos animais .

O objetivo deste trabalho foi avaliar o efeito do Cr orgânico veiculado em sal mineralizado sobre o peso corporal e ganho de peso de bovinos Nelore em pastagem.

\section{Material e métodos}

O experimento foi realizado em uma propriedade rural, localizada no Município de Jaguapitã, região Norte do Estado do Paraná $\left(23^{\circ}\right.$ de latitude sul e $51^{\circ}$ $30^{\prime}$ de longitude oeste e altitude aproximada de 550 m). O solo da região é do tipo Latossolo vermelho 
escuro, textura média e o clima caracterizado por subtropical úmido mesotérmico, conforme descrito pela Secretaria da Agricultura e do Abastecimento (PARANÁ, 1994).

A pesquisa totalizou 11 meses e foram utilizados 20 bezerros Nelores criados em condições de campo, desmamados ao início do experimento, com 6 meses de idade e com peso inicial médio de $179 \mathrm{~kg}$. Os animais foram inicialmente tratados contra ecto e endoparasitas e vacinados contra febre aftosa e clostridioses. Em função das necessidades, repetiu-se o tratamento contra ecto e endoparasitas, além de reforço imunoprofilático contra as doenças anteriormente citadas.

No início do experimento os animais foram separados ao acaso, identificados com brincos coloridos numerados e fixados na parte média da orelha esquerda. Os animais foram pesados e distribuídos em um delineamento inteiramente casualizado, em dois tratamentos: com suplementação de $\mathrm{Cr}$ e sem suplementação (controle).
Os animais foram mantidos em pastagem de Brachiaria brizantha e Brachiaria decumbens na proporção de $50 \%$ de cada variedade, dividida em seis piquetes de 1 hectare (ha), sob lotação rotacionada com permanência de dez dias em cada piquete. Os piquetes foram separados por cercas eletrificadas compostas por três fios de arame, com distância de $0,30 \mathrm{~m}$ entre os fios, sendo que o primeiro foi eletrificado a $0,45 \mathrm{~m}$ do solo (PY, 1998). O local contou com duas áreas destinadas à suplementação; cada uma contendo um bebedouro e um cocho coberto para suplementação mineral com $10 \mathrm{~cm} /$ linear/cabeça (AGUIRRE; GHELFI FILHO, 1994) com duplo acesso.

A fonte de $\mathrm{Cr}$ utilizada foi a Carboaminofosfoquelato de $\mathrm{Cr}$ na dose de $1 \mathrm{mg} /$ animal/dia misturada ao sal mineralizado iônico. Para o grupo controle foi fornecido o mesmo sal mineralizado iônico sem o Cr. Para ambos os grupos a estimativa de consumo foi de $50 \mathrm{~g} / \mathrm{animal} / \mathrm{dia}$. A composição química do suplemento mineral está detalhada na Tabela 1.

Tabela 1. Fórmula do sal mineral iônico fornecido em níveis de garantia por Kg do produto.

\begin{tabular}{lcc}
\hline & Grupo suplementado & Grupo controle \\
\hline Cálcio (g) & 140 & 140 \\
Fósforo (g) & 65 & 65 \\
Enxofre (g) & 9 & 9 \\
Magnésio (g) & 5 & 5 \\
Sódio (g) & 148 & 148 \\
Cobalto (mg) & 107 & 107 \\
Cobre (mg) & 1500 & 1500 \\
Iodo (mg) & 150 & 150 \\
Manganês (mg) & 1100 & 1100 \\
Níquel (mg) & 30 & 30 \\
Selênio (mg) & 14 & 14 \\
Zinco (mg) & 4200 & 4200 \\
Flúor (máx)(mg) & 650 & 650 \\
Ferro (mg) & 1120 & 1120 \\
Cromo (mg) & $\mathbf{2 0}$ & - \\
\hline
\end{tabular}

Solubilidade do fósforo (P) em ácido cítrico a 2\% ( $\mathrm{min}$ ) - 95\% 
Os animais foram pesados no início do experimento e a cada 10 dias, nos primeiros 40 dias e posteriormente a cada 28 dias até o final. As pesagens foram realizadas pela manhã, após quatorze horas de jejum de alimentos sólidos e líquidos. $\mathrm{O}$ ganho de peso foi estabelecido pelas diferenças de pesos vivos de cada avaliação.
O índice pluviométrico foi obtido através da instalação de um pluviômetro, no local do experimento. Os dados foram coletados diariamente, às 8 horas, e expressos de forma acumulada para cada período. A média histórica regional foi obtida junto ao Instituto Agronômico do Paraná - IAPAR (2005) conforme destacado na Tabela 2.

Tabela 2. Precipitação pluviométrica, em mm, acumulada por período, durante o experimento e média histórica regional de 1972 a 2004 (IAPAR, 2005)

\begin{tabular}{lcc}
\hline & Meses & Precipitação mm \\
\hline junho & $\mathbf{2 0 0 3}$ & Média Histórica \\
julho & 41 & 88,3 \\
agosto & 39 & 55,4 \\
setembro & 74 & 50,3 \\
outubro & 97 & 112,9 \\
novembro & 180 & 135,3 \\
dezembro & 123 & 150,9 \\
\hline & 43 & 200 \\
\hline janeiro & $\mathbf{2 0 0 4}$ & Média Histórica \\
fevereiro & 97 & 220,2 \\
março & 101 & 167,1 \\
abril & 102 & 130,4 \\
maio & 74 & 100,4 \\
\hline
\end{tabular}

Fonte: IAPAR (2005).

O experimento caracterizou-se em delineamento inteiramente casualizado com dois tratamentos e dez repetições por tratamento. Os dados foram submetidos às análises estatísticas utilizando-se o Programa Sistema para Análises Estatísticas e Genética - SAEG, da Universidade Federal de Viçosa - UFV (1997). Utilizou-se o teste de Tukey para comparação de médias, adotando-se nível de significância de 5\%.

\section{Resultados e discussão}

Ao analisar os resultados foi observado efeito significativo $(\mathrm{P}<0,05)$ dos tratamentos para a variável peso vivo, sendo o tratamento suplementado com cromo o que apresentou maior média, 258,20 kg aos 210 dias de idade (Tabela 3). Já para o ganho de peso, apesar de não ter sido detectada diferença significativa $(\mathrm{P}>0,05)$ entre os tratamentos, os animais suplementados com cromo estavam, em média, 5\% mais pesados que aqueles sem suplementação (Tabela 3). 
Tabela 3. Peso médio final (PM) e ganho de peso (GP), em (kg), para os grupos controle e suplementado com cromo.

\begin{tabular}{lcc}
\hline \multicolumn{1}{c}{ Tratamento } & PM & GP \\
\hline Controle & $252,28 \mathrm{~B}$ & $11,42 \mathrm{~A}$ \\
Suplementado com cromo & $258,20 \mathrm{~A}$ & $12,00 \mathrm{~A}$ \\
\hline Média Geral & 255,24 & 11,71 \\
C.V.(\%) & 7,22 & 104,14 \\
\hline
\end{tabular}

* Médias na coluna seguidas de letras maiúsculas diferentes, diferem estatisticamente $(\mathrm{P}<0,05)$ pelo teste Tukey.

O coeficiente de variação obtido para ganho de peso foi alto, devido ao fato de alguns animais apresentarem valores negativos em alguns períodos. Estes coincidem com períodos onde a precipitação pluviométrica média foi baixa, ficando abaixo da média histórica (Tabela 2), associado a alta temperatura, comprometendo a qualidade da pastagem, única fonte de alimento disponível.

A menor qualidade da pastagem e o provável menor consumo devem ter acarretado menor digestibilidade da pastagem e menor quantidade de nutrientes disponíveis para o desempenho dos animais.

Houve efeito quadrático dos dias de pesagens sobre o peso corporal e sobre o ganho de peso $(\mathrm{P}<0,01)$, como pode ser observado nas figuras 1 e 2, respectivamente. O estudo da análise de regressão revelou efeitos quadráticos dos dias de pesagens sobre o peso corporal médio, para os dois tratamentos, sendo de modo geral, observado que o tratamento com cromo foi ligeiramente superior ao tratamento sem cromo. Efeitos quadráticos dos dias de pesagens foram também observados para o ganho de peso diário. Maior ganho de peso foi obtido pelos animais suplementados com cromo, $18,31 \mathrm{Kg}$ aos 192 dias de idade.

O desempenho em ganho de peso é um parâmetro freqüentemente avaliado em animais suplementados com $\mathrm{Cr}$ e os resultados encontrados na literatura são muito diferentes. Alguns autores têm encontrado efeito da suplementação do Cr sobre o desempenho de bovinos, principalmente quando estes estão submetidos a estresse. Para animais em conforto ambiental, a maior parte dos trabalhos, encontrados na literatura, não observaram efeitos da suplementação.

Os resultados desse experimento concordam com os de Chang e Mowat (1992) que estudaram os efeitos da suplementação com 0,4 ppm de $\mathrm{Cr}(\mathrm{Cr}$ levedura) em dois períodos. No primeiro período, considerado de estresse, a suplementação propiciou aumento do ganho de peso dos animais tratados em relação ao grupo testemunha. No segundo período, sem efeito de estresse, os animais suplementados com $\mathrm{Cr}$ apresentaram o mesmo desempenho dos que os sem suplementação.

Melo (2002) também obteve aumento no ganho de peso de bezerros Holandeses suplementados com $1 \mathrm{mg} /$ animal/dia de carboaminofosfoquelato de Cr. A suplementação com Cr orgânico foi efetiva no ganho de peso a partir do terceiro período do experimento, período no qual aumentou o estresse calórico em função de elevação na temperatura ambiental.

No experimento de Pechová et al. (2002), os resultados da suplementação com $5 \mathrm{mg} /$ animal/dia de $\mathrm{Cr}$ levedura foram favoráveis para o ganho de peso diário, no primeiro período de confinamento de novilhos de engorda e não favoráveis ao elevar a dose para $8 \mathrm{mg} /$ animal/dia, para o período de acabamento. 


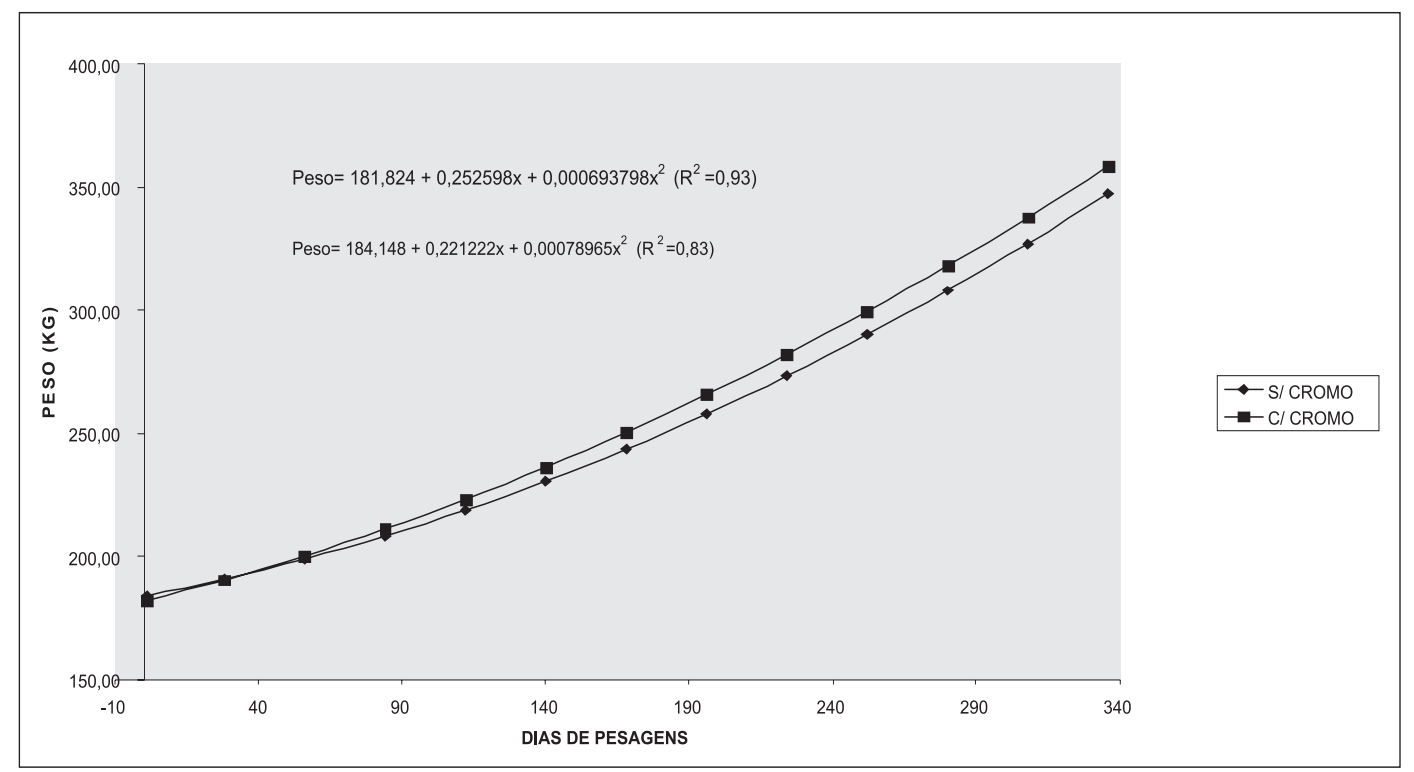

Figura 1. Peso corporal médio $(\mathrm{kg})$ para os animais controle e suplementados com cromo

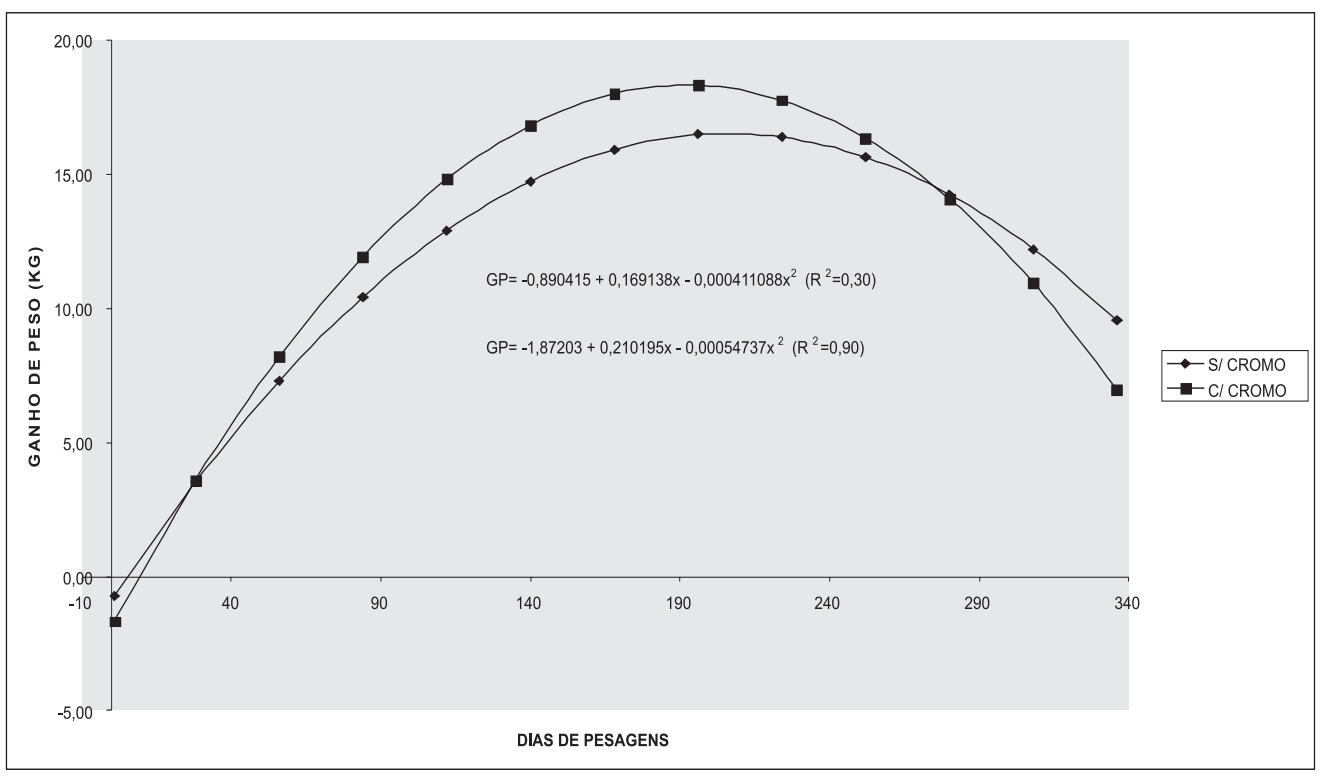

Figura 2. Ganho de peso $(\mathrm{kg})$ para os animais controle e suplementados com cromo

Uma das explicações para o melhor desempenho somente dos animais sob estresse é que, nestas condições, eles podem apresentar uma queda na resistência imune, queda essa que comprometeria o desempenho e, que, a suplementação visando elevar os níveis de $\mathrm{Cr}$, a evitaria, como já comprovado em vários experimentos (BURTON; MALLARD; MOWAT, 1993; MOONSIE-SHAGEER; MOWAT, 1993).
No entanto, no experimento de Kegley, Galloway e Fakler (2000) a suplementação de novilhos cruzados em crescimento, sob estresse, com 400 ou $800 \mathrm{mg} / \mathrm{kg}$ de dieta de Cr L-metionina por 24 dias não obtiveram efeito da suplementação sobre ganho de peso médio diário, ingestão de matéria seca e taxa de conversão alimentar. Outras fontes de Cr também não têm sido eficazes em promover efeito no ganho de peso, tais como cloreto de $\mathrm{Cr}$, e complexo de 
Cr ácido-nicotínico (KEGLEY; SPEARS, 1995) ou Cr quelato (MATHISON; ENGSTROM, 1995; WRIGHT; MALLARD; MOWAT, 1995). Por outro lado, o suplemento de $\mathrm{Cr}$, como $\mathrm{Cr}$ levedura (CHANG; MOWAT, 1992; MOONSIE-SHAGEER; MOWAT, 1993) aumentou o ganho de peso em alguns experimentos. Estes resultados variáveis podem refletir diferenças no "Status" de $\mathrm{Cr}$ em bovinos, o nível de estresse ao qual os bovinos estavam expostos, a quantia e biodisponibilidade de $\mathrm{Cr}$ na dieta basal ou a biodisponibilidade da fonte de Cr suplementar.

Zanetti et al. (2003), suplementando bezerros Holandeses, em condições de conforto, com $0,4 \mathrm{mg} / \mathrm{kg} / \mathrm{MS}$ de ração basal de $\mathrm{Cr}$ orgânico, não encontraram diferenças no ganho em peso, eficiência alimentar e conversão alimentar entre os grupos suplementados e não suplementados e sugeriram que em condições normais o $\mathrm{Cr}$ não tem apresentado efeito sobre o desempenho animal, devido provavelmente aos níveis das dietas serem suficientes para o adequado desenvolvimento do animal.

Os resultados de Zanetti et al. (2003) foram semelhantes aos obtidos por Swanson et al. (2000) que suplementaram novilhas de corte em crescimento por 6 semanas com 100, 200 ou $400 \mathrm{mg} / \mathrm{kg} / \mathrm{MS}$ da dieta com $\mathrm{Cr}$ levedura e não verificaram efeitos no ganho de peso diário e eficiência de ganho, sugerindo que a suplementação para bovinos em crescimento não estressados pode não ser benéfica.

\section{Conclusão}

A suplementação com Cromo orgânico em bovinos Nelore, em pastagem, influenciou positivamente o peso vivo dos animais. A adoção desta tecnologia possibilitou ganhos moderados de peso vivo que poderão reduzir a idade de abate, proporcionar maior produção e carne de melhor qualidade, melhorando assim a eficiência econômica da atividade.

\section{Referências}

AGUIRRE, J.; GHELFI FILHO, H. Instalações para bovinos. 2. ed. Campinas: CATI, 1994. 106 p. (Boletim Técnico, 204).

BURTON, J. L.; MALLARD, B. A.; MOWAT, D. N. Effects of supplemental chromium on immune responses of periparturient and early lactation dairy cows. Journal of Animal Science, Savoy, v. 71, n. 6, p. 1532-1539, 1993.

CHANG, X.; MOWAT, D. N. Supplemental chromium for stressed and growing feeder calves. Journal of Animal Science, Savoy, v. 70, n. 2, p. 559-565, 1992.

GALATI, R. L.; EZEQUIEL, J. B. Importância da suplementação mineral protéica durante a estação seca. 2003. Disponível em: < http://www.serrana.com.br/n boletins.asp?Tipo=n\&id=3>. Acesso em: 9 mar. 2005.

GOES, R. H. T. B.; MANCIO, A. B.; LANA, R. P.; VALADARES FILHO, S. C.; CECON, P. R.; QUEIROZ, A. C. ; LOPES, A. M. Desempenho de novilhos Nelore em pastejo na época das águas: ganho de peso, consumo e parâmetros ruminais. Revista Brasileira de Zootecnia, Viçosa, v. 32, n. 1, p. 214-221, jan./fev. 2003.

GOTTSCHALL, C. S.; OAIGEN, R. P.; MORAES, M. A.; VIERO, V.; SOUZA NETO, R. L.; SOARES, J. C. R. Análise bioeconômica de vacas de corte terminadas em regime de suplementação a campo e confinamento. ARS Veterinária, Jaboticabal, v. 20, n. 2, p. 151-159, 2004.

INSTITUTO AGRONÔMICO DO PARANÁ -IAPAR. Médias históricas das estações do IAPAR. Disponível em: $\quad<$ http//200.201.27.14/Site/Sma/Estaçoes_IAPAR/ Estacoes_Paraná.htm>. Acesso em: 9 mar. 2005.

KEGLEY, E. B.; GALLOWAY, D. L.; FAKLER, T. M. Effect of dietary chromium-L- methionine on glucose metabolism of beef steers. Journal of Animal Science, Savoy, v. 78, n. 12, p. 3177-3183, 2000.

KEGLEY, E. B.; SPEARS, J. W. Immune response, glucose metabolism, and performance of stressed feeder calves fed inorganic or organic chromium. Journal of Animal Science, Savoy, n. 73, n. 9, p. 2721-2726, 1995.

LOPES, F. C. F.; AROEIRA, L. J. M.; RODRIGUEZ, N. M.; DERESZ, F.; SAMPAIO, I. B. M.; PACIULLO, D. S. C.; VITTORI, A. Efeito da suplementação e do intervalo de pastejo sobre a qualidade da forragem e consumo voluntário de vacas Holandês x Zebu em lactação em pastagem de capim-elefante. Arquivo Brasileiro de Medicina Veterinária e Zootecnia, Belo Horizonte, v. 56, n. 3, p. 335-362, 2004. 
MATHISON, G. W.; ENGSTROM, D. F. Chromium and protein supplements for growing - finishing beef steers fed barley-based diets. Canadian Journal of Animal Science, Ottawa, v. 75, n. 4, p. 549-558, 1995.

MELO, G. M. P. Desempenho e parâmetros sangüíneos de bezerros submetidos a estresse, suplementados com o crômio orgânico. 2002. Tese (Doutorado em Zootecnia) - Universidade Estadual Paulista, Jaboticabal, 2002.

MERTZ, W. Chromium in human nutrition: a review. Journal Nutrition, Bethesda, v. 123, n. 4, p. 626-633, 1993.

MOONSIE-SHAGEER, S.; MOWAT, D. N. Effect of level supplemental chromium on performance, serum constituents, and immune status of stressed feeder calves. Journal of Animal Science, Savoy, v. 71, n. 1, p. 232-238, 1993.

MORAES, S. S. Novos microelementos minerais e minerais quelatados na nutrição de bovinos. Campo Grande: Embrapa Gado de Corte, 2001. (Documento, n. 119).

NATIONAL RESEARCH COUNCIL - NRC. Committee on Animal Nutrition. Nutrient requirement of beef cattle. Washington: National Academic Press, 1989.

PARANÁ. Secretaria da Agricultura e do Abastecimento. Manual técnico do subprograma de manejo e conservação do solo. Curitiba: SEAB, 1994. 372p.

PECHOVÁ, A.; ILLEK, J.; INDELÁ, M.; PAVLATA, L. Effects of chromium supplementation on growth rate and metabolism in fattening bulls. Acta Veterinaria Brno, Tchecoslovaquia, v. 71, n. 4, p. 535-541, 2002.
POLLARD, G. V.; RICHARDSON, C. R.; KARNEZOS, T. P. Effects of supplemental organic chromium on growth, feed efficiency and carcass characteristics of feedlot steers. Animal Feed Science and Technology, Amsterdam, v. 98, n. 1/2, p. 121-128, 2002.

PY, C. R. Rede física. In: Guaíba: Agropecuária, 1998. p. 55-58.

SWANSON, K. C.; HARMON, D. L.; JACQUES, K. A.; LARSON, B. T.; RICHARDS, C. J.; BOHNERT, D. W.; PATON, S. J. Efficacy of chromium-yeast supplementation for growing beef steers. Animal Feed Science and Technology, Amsterdam, v. 86, n. 1/2, p. $95-$ 105, 2000.

UNIVERSIDADE FEDERAL DE VIÇOSA - UFV. Manual de utilização do programa SAEG (Sistema para Análise Estatística e Genética). Viçosa: Fundação Arthur Bernardes, 1997. Versão 7.0.

WRIGHT, A. J.; MALLARD, B. A.; MOWAT, D. N. The influence of supplemental chromium and vaccines on the acute phase response of newly arrived feeder calves. Canadian Journal of Veterinary Research, Ottawa, v. 59, n. 4, p. 311-315. 1995.

ZANETTI, M. A.; SALLES, M. S. V.; BRISOLA, M. L.; CÉSAR, M. C. Desempenho e resposta metabólica de bezerros recebendo dietas suplementadas com cromo. Revista Brasileira de Zootecnia, Viçosa, v. 32, n. 6, p. 1532-1535, 2003. 